\title{
Genetic polymorphism of Cytochrome-P450-2C9 (CYP2C9) in Indian populations
}

Sheikh Nizamuddin, Shivendra Dubey, Sakshi Singh, Saurav Sharma, Anshuman Mishra, Harish K, Harsh Joshi, K. Thangaraj ${ }^{*}$

${ }^{\dagger}$ CSIR-Centre for Cellular and Molecular Biology, Hyderabad, Telangana, 500007, India

*Corresponding author

K. Thangaraj

CSIR-Centre for Cellular and Molecular Biology

Hyderabad, Telangana

India - 500007

Fax number: +91-40-27160311/27160591 


\section{Abstract}

Cytochrome-P450-2C9 (CYP2C9) metabolizes wide range of drugs and highly express in human liver. Various mutations of CYP2C9 (R144C, I359L etc.), associated with drugresponse, are highly diverse. We aimed to investigate the genetic diversity of CYP2C9 in Indian-subcontinent, using 1278 subjects from 36 populations. High frequency of $C Y P 2 C 9 * 3$ (0-0.179) was observed, comparative to other populations, including Europeans. Subjects having $C Y P 2 C 9 * 3 / * 3$ requires lower dose of warfarin, comparative to $C Y P 2 C 9 * 1 / * 3$ or CYP2C9*1/*1. Since, Indians are practicing marriage among their caste system, we predicted and observed high frequency $(0-0.05)$ of $C Y P 2 C 9 * 3 / * 3$. Out of 21 populations, living outside of Indian subcontinent, only Toscani and Southern Han-Chinese have 0.009 and 0.01 CYP2C9*3/*3, respectively, lower than Indians,. We found a non-synonymous mutation (L362V), observed only in Indian-subcontinent, and have 0-0.056 allelic, 0-0.037 L/V and 0$0.037 V / V$ genotype frequency. We observed unfavorable interatomic interactions between hydroxylation sites of warfarin and reactive oxyferryl heme in mutant, comparative to wildtype CYP2C9, in molecular dynamic simulations; and predict lower kinetic activity. 


\section{Introduction}

Heterogeneous drug response is the major hurdle in the successful treatment of diseases and depends on the genetic variations of drug metabolizing enzyme genes. Cytochrome P450 (CYP) family is an important enzyme of ADME (related to absorption, distribution, metabolism and excretion of drug) genes, of which CYP2C9 is the major constituent of CYP2C subfamily in human liver. It metabolizes wide range of drugs including anticoagulant (warfarin), non-steroidal anti-inflammatory (celecoxib, diclofenac), anti-diabetic (netaglinide, tolbutamide), anti-hypertensive (irbesartan, losartan) and anti-epileptic (phenytoin) ${ }^{1}$. Several variations in CYP2C9 have been reported which affects metabolism of the drug. Most notable variations are CYP2C9*2 (R144C) and CYP2C9*3 (I359L) which decreases $12 \%$ and $5 \%$ enzyme activity, respectively ${ }^{2}$. Interestingly, these variations are highly heterogeneous among world population; (1) 8-19\% and 3.3-16.3\% in Caucasian; (2) 0-0.1\% and 1.1-3.6\% in Asian; (3) 2.9\% and 2.0\% in African-American; and (4) $0-4.3 \%$ and $0-2.3 \%$ in Black/African, respectively ${ }^{3}$. Moreover, other rare and functionally relevant variations were also reported in various populations, which includes; (1) CYP2C9*6, 0.6\% frequency in African-Americans ${ }^{4}$; (2) CYP2C9*4, 0.5\% in African-Americans and 6\% in Caucasians 2, 5; and (3) CYP2C9*13, 0.19-0.45\% in Asian ${ }^{6}$. Recently, Dai et al. (2013) reported several rare variants in the Han Chinese population ${ }^{7}$.

Several studies have been performed on CYP2C9 in Indian populations. However, most of studies focused only on CYP2C9*3 and CYP2C9*2. Recently, Anil et al (2014) found that CYP2C9*3 present only in Indo-European population with $0.38-1.85 \%$, while absent in Dravidian, Austro-Asiatic and Tibeto-Burman populations ${ }^{8}$. Indian populations are well known for their endogamy practices and must have very high frequency of homozygous 
allele $^{9}$, however, Anil et al (2014) did not observe any homozygous CYP2C9*3/*3 genotype. Many studies have shown that the variations in CYP2C9 are associated with therapeutic heterogeneity in Indian populations. CYP2C9*2 and *3 has been reported with less hydroxylation (or metabolism) of phenytoin in vivo in South-Indian populations ${ }^{10}$, comparative to wild type CYP2C9*1. Ramasamy et al. (2007) reported phenytoin toxicity in a patient with normal dose of $300 \mathrm{mg} /$ day, who had $C Y P 2 C 9 * 3 / * 3$ genotype ${ }^{11}$. The same symptoms were reported by Thakkar, A. N. et al. (2010) in South-Indian populations ${ }^{12}$. Many studies have also demonstrated that the Indian populations need high dose of warfarin and phenytoin compared to Caucasians ${ }^{12}$. Both of these drugs are metabolized by CYP2C9. Some of the drugs, metabolized by CYP2C9 have narrow therapeutic index e.g. warfarin, phenytoin and tolbutamide. This is the reason that small change in the activity of CYP2C9 may cause major changes in individual's response.

Considering the high genetic diversity in Indian sub-continent, we explore functionally relevant variations in CYP2C9, in the present study. The outcome can be utilized to understand heterogeneous therapeutic response and in development of personalized therapy in Indian sub-continent.

\section{Material and methods}

\section{Details of samples}

In total, 1278 samples were selected for the study. To find the distribution of CYP2C9 allele/genotype frequency within Indian subcontinent, 36 populations of different linguistic groups and geographical locations were selected (Table S1) ${ }^{9,}{ }^{13}$; and further compared with 
populations of 1000 genome project. Present work has been approved by the Institutional Ethical Committee of CSIR-Centre for Cellular and Molecular Biology (CSIR-CCMB), Hyderabad, India. Informed written consent has been obtained from every participant, prior to collection of blood samples.

\section{Re-sequencing of CYP2C9, genotyping and analysis}

All the 9 exons, their respective intron-exon boundary, 3' and 5' UTR of CYP2C9 have been resequenced. For designing of primer, DNA sequence of ENST00000260682 from Ensembl (v75) has been used. Out of 3 mRNA of CYP2C9, only ENST00000260682 translate to protein. Primer3.0 web-based tool (http://simgene.com/Primer3) was used for designing the primers and further primers specificity were checked with NCBI-primer blast. The details of primer sequences are given in Table S2. Polymerase chain reaction (PCR) was performed in $10.0 \mu \mathrm{l}$ solution, which contains $5.0 \mu \mathrm{l}$ of 2x EmeraldAmp GT PCR master mix, 10-20 ng of genomic DNA and 0.1 pmole (final concentration) of each primer. Thermal cycling conditions used are as follows: initial denaturation step of 5 min at $94^{\circ} \mathrm{c}$, followed by 35 cycles of denaturation step of $30 \mathrm{sec}$ at $94^{\circ} \mathrm{C}$, annealing step of $30 \mathrm{sec}$ at their respective melting temperature, extension step of $2 \mathrm{~min}$ at $72^{\circ} \mathrm{C}$, followed by single step of final extension of $7 \mathrm{~min}$ at $72^{\circ} \mathrm{C}$. PCR products were cleaned with Exo-SAP-IT (USB, Affymetrix, USA) with recommended protocol of the manufacturer. Cleaned PCR product $(1.0 \mu \mathrm{l})$ has been subjected to sequencing PCR using BigDye terminator (v3.1) cycle sequencing kit (Applied Biosystem, USA) and analyzed using ABI 3730xl DNA sequencer. AutoAssembler (v1.0) was used for assembling and manual editing of sequence data.

\section{Distal effect of L362V on kinetics of CYP2C9: molecular dynamics simulation}


Preparation of 3D (3 dimensional) structure

We performed the molecular dynamics simulation with Gromacs (version 5.0.2) ${ }^{14}$. Starting structure of CYP2C9 was obtained from PDB (code: 1OG5). We removed warfarin drug from 1OG5 with Chimera (version 1.11) ${ }^{15}$ and utilized in the further structure modifications. In total, 7 amino acids (K206E, I215V, C216Y, S220P, P221A, I223L and I224L) were substituted in wild type CYP2C9, to enhance the crystallization ${ }^{16}$. Hence, we modified back 1OG5 to wild type sequence with FoldX (version 2.6) and further utilized to generate mutant proteins. We generated 3D structure of L362V, with FoldX.

Docking of warfarin drug

Since, warfarin was located farther from heme center and in catalytically non-reactive stage; we performed docking with AutoDock Vina (version 1.1.2) to obtain putative functional confirmation of drug in the active site of $C Y P 2 C 9^{17}$. Autodock tools were used for generating partial charges of warfarin and CYP2C9 using Gasteiger method ${ }^{18}$. Confirmation of warfarin, having lowest binding energy, was selected in further analysis.

\section{Simulation}

To perform molecular dynamics simulation, Gromacs (version 5.0.2) was used ${ }^{14}$. We assigned the partial charges of warfarin and oxyferryl state of heme group, as described by Seifert, A et. al (2006) ${ }^{19}$, while for generating partial charges in wild-type/mutant protein, we used Amber force field “ff99SB". Before assigning partial charges and structure 
modifications, we removed $\mathrm{H}$ atom from ligand bound protein, with Babel software ${ }^{20}$. Further, structure was loaded in Tleap (AmberTools) ${ }^{21}$ to modify; (1) creating single bond SFe, (S of CYM406 and Fe of heme group), (2) creating single bond Fe-O (Fe of heme group and $\mathrm{O}$ of water molecule $/ \mathrm{H}_{2} \mathrm{O} 464$ ) and (3) removal of $\mathrm{H}$ atom from $\mathrm{H}_{2} \mathrm{O} 464$.

For all ligand bound models (wild-type/mutant), initially we placed the molecule in $1 \mathrm{~nm}$ cubic box and then solvated it with TIP3P water molecules; and neutralize the system with sodium (NA) molecules. Energy minimization of the system was performed in 10,000 steps with steepest descent minimization algorithm. The potential energy of system has been demonstrated in Figure S1. Further, we equilibrated the system at $~ 310 \mathrm{~K}$ (normal human body temperature) and at pressure $\sim 1$ bar in 20 and 100 pico seconds (ps) respectively in 2 different steps (Figure S2). After this, system was simulated for 15 nano seconds (ns), in 4 replicates. To calculate the rolling mean in $100 \mathrm{ps}$, we utilized the zoo package of $\mathrm{R}^{22}$.

\section{Results and discussions}

\section{Diversity of CYP2C9*3 in Indian populations}

The $\mathrm{A} \rightarrow \mathrm{C}$ (rs1057910/ CYP2C9*3) is a non-synonymous mutation, which replace Isoleucine with Leucine (ATT>CTT; Ile359Leu; low enzyme activity). Considering the higher level of evidence between CYP2C9*3 and drug response, CPIC (Clinical Pharmacogenomics Implementation Consortium) has been categorized $C Y P 2 C 9 * 3$ under level-1A ${ }^{23} \cdot C Y P 2 C 9 * 3$ has been reported with hypersensitive reaction against phenytoin in epilepsy patients ${ }^{24}$, decreased metabolism of celecoxib ${ }^{25}$. It is also reported with high incident of response rate against sulfonamides, urea derivatives ${ }^{26}$. 
To explore the “C” allele frequency in Indian populations, initially we confirmed HardyWeinberg equilibrium (HWE). It was observed that 10 populations were not in HWE ( $p$-value $<0.05$ ), which include 1 Indo-European population, Haryana Pandit ( $\mathrm{p}$-value $=1.3 \times 10^{-4}$ ) and 9 Dravidians populations; Mudaliar and Madar from Tamil Nadu (p-value $=1.92 \times 10^{-6}$ and $4.75 \times 10^{-7}$ respectively), Gawali from Karnataka ( $\mathrm{p}$-value $\left.=4.12 \times 10^{-4}\right)$, Kurumba from Kerala $\left(\mathrm{p}\right.$-value $\left.=6.94 \times 10^{-6}\right)$ and Telagas, Thoti, Chenchu, Patkar and Vaddera from Andhra Pradesh (p-value $=1.6 \times 10^{-3}, 2.23 \times 10^{-8}, 0,5.21 \times 10^{-6}$ and $6.99 \times 10^{-3}$ respectively) $($ Table $\mathbf{1})$.

After excluding these 10 populations, we estimated 11.67\% (183 out of 1568) “C” allele in Indian populations, similar $(\mathrm{p}$-value $=0.617)$ to South-Asian populations of 1000 genome project. Further, we categorized these samples on the basis of their linguists and observed that Dravidians have higher percentage of "C" allele (15.32\%; 72 out of 470$)$ while TibetoBurman have lowest (6.12\%; 6 out of 92). Moreover, in Austro-Asiatics and Indo-European, we observed 9.96\% (46 out of 416) and 10.96\% (59 out of 538), respectively (Table 1). Interestingly, Tibeto-Burman are insignificantly different $(p$-value $=0.21)$ from East-Asians. Adi-Dravidians (schedule tribe) of TamilNadu, Ho (schedule tribe) of Jharkhand and Baiswar (caste) of Uttar-Pradesh have 17.857\%, 15.385\% and 16.176\% of CYP2C9*3, respectively, which is higher in their respective linguistic group; while Bhil of Gujarat, Raj-Gond of Madhya-Pradesh and Gond of Chhattisgarh have $0 \%, 0 \%, 2 \%$, respectively (Table 1). In Indian sub-continent, high local heterogeneity was observed and any correlation with geographical location does not exist (Figure 1A and Table 1). It is evident in isofrequency map that Indian populations have high frequency of $C Y P 2 C 9 * 3$, comparative to other world populations (Figure 1A). We observed, decreasing gradient of “C” allele frequency from Indian subcontinent to Europeans (Figure 1A). 
On the basis of founder events and endogamy marriage practices, we have already predicted high frequency of homozygous alleles in Indian populations ${ }^{9}$. Since, patients with CYP2C9*3/*3 requires lower dose $(0.5-2 \mathrm{mg})$ of warfarin in comparison to those who have CYP2C9*1/*3 (3-4 mg), it would be interesting to explore in Indian populations. As expected, we observed higher percentage $(<5 \%)$ of $C Y P 2 C 9 * 3 / * 3$ in Indians, comparative to other world populations, who have $0-1 \%$ (Figure 1B and Table 1). Out of 21 populations who are living out of Indian subcontinent, only TSI (Italian populations) and CHS (South Chinese populations) have homozygous genotype (0.9 and 1\%), while out of 5 populations who are living in Indian sub-continent, 3 (PJL, ITU and GIH) have 1\% CYP2C9*3/*3. In present Indian populations samples, we observed $0-5 \% C Y P 2 C 9 * 3 / * 3$, of which Bhilala of Madhya-Pradesh and Ho of Jharkhand have 5\% and 3\%, respectively; higher in IndoEuropeans and Austro-Asiatic linguistic group (Table 1). We observed $0 \% C Y P 2 C 9 * 3 / * 3$ in Tibeto-Burman. Since, CYP2C9*3/*3 was not in HWE in Dravidian populations, we did not concluded the frequency.

\section{Novel non-synonymous variant L362V}

We observed a non-synonymous mutation L362V in Indian population at higher frequency. Since, this mutation was observed in higher frequency and present only in Indian populations; we further explored it in 1000 genome project samples. We found that this variant (rs578144976; L362V) was reported at very low frequency $(0.4 \%)$ in South-Asians, while absent in other world populations. Only ITU (Telugu population) and BEB (Bengali population) are reported to have $0.6 \%$ and $1.5 \%$ (http://browser.1000genomes.org/Homo_sapiens/Variation/Population?db=core;g=ENSG000 
00138109;r=10:96698415-96749147;v=ss1338631398;vdb=variation;vf=75731685).

Indian sub-continent, it was observed in all four linguistic groups (13 populations). After excluding the populations in which L362V is not in HWE, we observed 0-5.6\% allele, 03.7\% heterozygous and 0-3.7\% homozygous mutant genotype frequency (Table 2, Figure 2A and 2B). It can be hypothesize that $\mathrm{L} 362 \mathrm{~V}$ is originated recently in Indian sub-continent and due to long-term isolation of Indian populations with rest of the world, it was observed only in this region. This might be the reason also, why L362V, deviated from HardyWeinberg equilibrium in many populations.

\section{Effect of L362V: In-Silico prediction}

Lertkiatmongkol, P. et. al $(2013)^{27}$ predicted distal effect of amino acid substitution in CYP2C9 in molecular dynamics simulation. Authors observed that distance between hydroxylation sites of warfarin and reactive oxyferryl heme in mutant (CYP2C9*3: FeO-

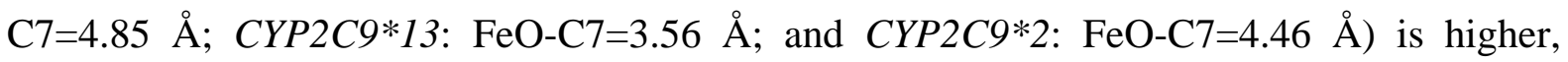
comparative to wild type protein (FeO-C7=3.30 $\AA$ ). This unfavorable interatomic interaction is the reason of lower kinetic activity in mutant proteins. We utilized same molecular dynamics simulation to explore the distal effect of L362V on the kinetic activity of CYP2C9, comparative to wild type protein.

We performed 4 different simulations for wild type and mutant (L362V) CYP2C9, after redocking warfarin in active site (Figure 3) and equilibrating system (Figure S2). The system contains water molecular and wild-type/mutant CYP2C9 in $1 \times 1 \times 1 \mathrm{~nm}^{3}$ cubic box, neutralized by sodium ion $\left(\mathrm{Na}^{+}\right)$. We observed that in all 4 simulations, wild-type and mutant CYP2C9 protein were in stable state [radius of gyration $\left(R_{g}\right)$; for wild type, $1^{\text {st }}: 2.249 \pm 0.0062,2^{\text {nd }}$ : 
$2.246 \pm 0.0058,3^{\text {rd }}: 2.243 \pm 0.0058$ and $4^{\text {th }}: 2.247 \pm 0.0064$; for mutant, $1^{\text {st }}: 2.266 \pm 0.0104,2^{\text {nd }}$ : $2.263 \pm 0.0062,3^{\text {rd }}: 2.59 \pm 0.0062$ and $\left.4^{\text {th }}: 2.253 \pm 0.0058\right]$ (Figure S3). Hydroxylation at C6, C7 and C4 of warfarin needs the hydrogen bond between H6, H7 and H4 of warfarin and FeO (oxygen) of oxyferryl heme. Therefore, we consider only those confirmations in active state, which are having rolling mean distance of $\mathrm{H}^{\cdots \cdots} \mathrm{O}<3 \AA$ (distance of $\mathrm{C}-\mathrm{H}^{\cdots \cdots} \mathrm{O}$ ). We observed unfavorable interatomic interactions for hydroxylation between (1) $\mathrm{H} 6$ and $\mathrm{FeO}$ and (2) $\mathrm{H} 7$ and $\mathrm{FeO}$ in simulation of mutant, comparative to wild-type CYP2C9 (Figure 4, 6 and S4). The simulations predict the less kinetic activity of the mutant (L362V) CYP2C9, comparative to wild-type.

\section{Other rare variants}

Besides these, a few rare variants have also been observed in this study. The nonsynonymous C>T mutation (rs28371685), which replace arginine with tryptophan (R335W) and determine CYP2C9*11 haplogroup was found only in 3 individuals $(0.2347 \%, 1$ each in Chenchu, Telagas of Andhra Pradesh and Mudliar of Tamil Nadu). Besides this, 2 novel nonsynonymous mutations F482L and T283S were found in 2 individual (0.0782\%), each in Mizo (Mizoram) and Warli (Maharashtra), respectively.

Acknowledgements: This work was supported by CSIR Network project-EpiHeD (BSC0118), Government of India. Sheikh Nizamuddin was supported by ICMR JRF-SRF research fellowship. We acknowledge Dr. Gyaneshwar chaubey, for kindly preparing the isofrequency map with Surfer software (version 10). We also acknowledge Dr. Ravi Kumar Verma, who helped us in molecular dynamics simulation.

Conflict of interests: The authors declare no conflict of interest. 


\section{Figure legend}

Figure 1. Isofrequency map of (A) CYP2C9*3 and (B) CYP2C9*3/*3 to demonstrate the geospatial distribution. We excluded those populations who were not in HWE. In map, dots represent the sampling location.

Figure 2. Isofrequency map of novel mutant L362V. Figure (A) and (B) represents the allelic and genotype geospatial distribution. Similar to figure 1, we excluded those populations who were not in HWE.

Figure 3. Confirmation of warfarin in (A) original 3D structure (1OG5), dowloaded from PDB and (B) after re-docking.

Figure 4. Distance between FeO of oxyferryl heme group and hydrogen atom (H6) bound to C6 of warfarin. The middle orange line represents rolling mean of distance with window size of 100 ps while blue line represents the cut-off value $(<3 \AA)$ for favorable hydrogen bond. Hydrogen atom H6 attains favorable interactions for hydroxylation (H-bond $<3 \AA$ ) only in wild-type CYP2C9 (during $1^{\text {st }}, 2^{\text {nd }}$ and $3^{\text {rd }}$ molecular dynamics simulation).

Figure 5. Distance between FeO of oxyferryl heme group and $\mathrm{H7}$ of warfarin. Orange and blue lines represents similar values, given in figure 4. Hydrogen atom H7 attains favorable interactions for hydroxylation (H-bond $<3 \AA$ ) only in wild-type CYP2C9 (during $2^{\text {nd }}$ molecular dynamics simulation). 


\section{References}

1. Miners JO, Birkett DJ. Cytochrome P4502C9: an enzyme of major importance in human drug metabolism. Br J Clin Pharmacol 1998; 45(6): 525-538.

2. Sullivan-Klose TH, Ghanayem BI, Bell DA, Zhang ZY, Kaminsky LS, Shenfield GM, et al. The role of the CYP2C9-Leu359 allelic variant in the tolbutamide polymorphism. Pharmacogenetics 1996; 6(4): 341-349.

3. Yasuda SU, Zhang L, Huang SM. The role of ethnicity in variability in response to drugs: focus on clinical pharmacology studies. Clin Pharmacol Ther 2008; 84(3): 417-423.

4. Kidd RS, Curry TB, Gallagher S, Edeki T, Blaisdell J, Goldstein JA. Identification of a null allele of CYP2C9 in an African-American exhibiting toxicity to phenytoin. Pharmacogenetics 2001; 11(9): 803-808.

5. Kimura M, Ieiri I, Mamiya K, Urae A, Higuchi S. Genetic polymorphism of cytochrome P450s, CYP2C19, and CYP2C9 in a Japanese population. Ther Drug Monit 1998; 20(3): 243-247.

6. Si D, Wang J, Zhang Y, Zhong D, Zhou H. Distribution of CYP2C9*13 allele in the Chinese Han and the long-range haplotype containing CYP2C9*13 and CYP2C19*2. Biopharm Drug Dispos 33(6): 342-345.

7. Dai DP, Xu RA, Hu LM, Wang SH, Geng PW, Yang JF, et al. CYP2C9 polymorphism analysis in Han Chinese populations: building the largest allele frequency database. The pharmacogenomics journal 2014; 14(1): 85-92. 
8. Giri AK, Khan NM, Grover S, Kaur I, Basu A, Tandon N, et al. Genetic epidemiology of pharmacogenetic variations in CYP2C9, CYP4F2 and VKORC1 genes associated with warfarin dosage in the Indian population. Pharmacogenomics 2014; 15(10): 1337-1354.

9. Reich D, Thangaraj K, Patterson N, Price AL, Singh L. Reconstructing Indian population history. Nature 2009; 461(7263): 489-494.

10. Rosemary J, Surendiran A, Rajan S, Shashindran CH, Adithan C. Influence of the CYP2C9 AND CYP2C19 polymorphisms on phenytoin hydroxylation in healthy individuals from south India. The Indian journal of medical research 2006; 123(5): 665-670.

11. Ramasamy K, Narayan SK, Chanolean S, Chandrasekaran A. Severe phenytoin toxicity in a CYP2C9*3*3 homozygous mutant from India. Neurology India 2007; 55(4): 408-409.

12. Thakkar AN, Bendkhale SR, Taur SR, Gogtay NJ, Thatte UM. Association of CYP2C9 polymorphisms with phenytoin toxicity in Indian patients. Neurology India 2012; 60(6): 577-580.

13. Moorjani P, Thangaraj K, Patterson N, Lipson M, Loh PR, Govindaraj P, et al. Genetic evidence for recent population mixture in India. Am J Hum Genet 93(3): 422-438.

14. Van Der Spoel D, Lindahl E, Hess B, Groenhof G, Mark AE, Berendsen HJ. GROMACS: fast, flexible, and free. Journal of computational chemistry 2005; 26(16): 1701-1718. 
15. Pettersen EF, Goddard TD, Huang CC, Couch GS, Greenblatt DM, Meng EC, et al. UCSF Chimera--a visualization system for exploratory research and analysis. Journal of computational chemistry 2004; 25(13): 1605-1612.

16. Williams PA, Cosme J, Ward A, Angove HC, Matak Vinkovic D, Jhoti H. Crystal structure of human cytochrome P450 2C9 with bound warfarin. Nature 2003; 424(6947): 464-468.

17. Trott O, Olson AJ. AutoDock Vina: improving the speed and accuracy of docking with a new scoring function, efficient optimization, and multithreading. Journal of computational chemistry 2010; 31(2): 455-461.

18. Morris GM, Huey R, Lindstrom W, Sanner MF, Belew RK, Goodsell DS, et al. AutoDock4 and AutoDockTools4: Automated docking with selective receptor flexibility. Journal of computational chemistry 2009; 30(16): 2785-2791.

19. Seifert A, Tatzel S, Schmid RD, Pleiss J. Multiple molecular dynamics simulations of human p450 monooxygenase CYP2C9: the molecular basis of substrate binding and regioselectivity toward warfarin. Proteins 2006; 64(1): 147-155.

20. O'Boyle NM, Banck M, James CA, Morley C, Vandermeersch T, Hutchison GR. Open Babel: An open chemical toolbox. Journal of cheminformatics 2011; 3: 33.

21. Case DA, Cheatham TE, 3rd, Darden T, Gohlke H, Luo R, Merz KM, Jr., et al. The Amber biomolecular simulation programs. Journal of computational chemistry 2005; 26(16): 1668-1688.

22. Grothendieck AZG. zoo: S3 Infrastructure for Regular and Irregular Time Series. Journal of Statistical Software 2005; 14(6): 27. 
23. Thorn CF, Klein TE, Altman RB. PharmGKB: the Pharmacogenomics Knowledge Base. Methods in molecular biology (Clifton, NJ) 2013; 1015: 311-320.

24. Ramasamy K, Narayan SK, Shewade DG, Chandrasekaran A. Influence of CYP2C9 genetic polymorphism and undernourishment on plasma-free phenytoin concentrations in epileptic patients. Therapeutic drug monitoring 2010; 32(6): 762766.

25. Tang C, Shou M, Rushmore TH, Mei Q, Sandhu P, Woolf EJ, et al. In-vitro metabolism of celecoxib, a cyclooxygenase-2 inhibitor, by allelic variant forms of human liver microsomal cytochrome P450 2C9: correlation with CYP2C9 genotype and in-vivo pharmacokinetics. Pharmacogenetics 2001; 11(3): 223-235.

26. Zhou K, Donnelly L, Burch L, Tavendale R, Doney AS, Leese G, et al. Loss-offunction CYP2C9 variants improve therapeutic response to sulfonylureas in type 2 diabetes: a Go-DARTS study. Clinical pharmacology and therapeutics 2010; 87(1): $52-56$.

27. Lertkiatmongkol P, Assawamakin A, White G, Chopra G, Rongnoparut P, Samudrala $\mathrm{R}$, et al. Distal effect of amino acid substitutions in CYP2C9 polymorphic variants causes differences in interatomic interactions against (S)-warfarin. PLoS One 2013; 8(9): e74053. 
Table 1. Distribution of CYP2C9*3 (I359L ) in Indian populations

\begin{tabular}{|c|c|c|c|c|c|c|c|c|c|c|c|c|}
\hline \multirow[b]{2}{*}{ Populations } & \multirow[b]{2}{*}{ State } & \multirow[b]{2}{*}{ Lat. } & \multirow[b]{2}{*}{ Long. } & \multirow[b]{2}{*}{ Linguistic } & \multirow{2}{*}{$\begin{array}{l}\text { Sample } \\
\text { size }\end{array}$} & \multicolumn{6}{|c|}{ Genotype/Allele percentage (number of individuals): rs1057910 } & \multirow[b]{2}{*}{ HWE p-value } \\
\hline & & & & & & Missing data & AA & AC & CC & A & C & \\
\hline Mahli & Jharkhand & 23.46 & 85 & Austro-Asiatic & 38 & $4(10.526)$ & $27(79.412)$ & $6(17.647)$ & $1(2.941)$ & $60(88.235)$ & $8(11.765)$ & 0.3712145 \\
\hline Gond & Chattisgarh & 19.87 & 81.6 & Austro-Asiatics & 37 & $8(21.622)$ & $28(96.552)$ & $0(0)$ & $1(3.448)$ & $56(96.552)$ & $2(3.448)$ & 0.018 \\
\hline Kharia & Chattisgarh & 23.33 & 85.44 & Austro-Asiatics & 86 & $14(16.279)$ & $62(86.111)$ & $10(13.889)$ & $0(0)$ & 134(93.056) & $10(6.944)$ & 1 \\
\hline Gond & Madhya-Pradesh & 26.12 & 77.4 & Austro-Asiatics & 38 & $7(18.421)$ & $25(80.645)$ & $6(19.355)$ & $0(0)$ & $56(90.323)$ & $6(9.677)$ & 1 \\
\hline Ho & Jharkhand & 23.35 & 85.33 & Austro-Asiatics & 67 & $2(2.985)$ & 47(72.308) & $16(24.615)$ & $2(3.077)$ & $110(84.615)$ & $20(15.385)$ & 0.633 \\
\hline Kolhas & Andhra-Pradesh & 14.46 & 79.98 & Dravidian & 14 & $2(14.286)$ & $10(83.333)$ & $2(16.667)$ & $0(0)$ & $22(91.667)$ & $2(8.333)$ & 1 \\
\hline Adi-Dravidar & Tamilnadu & 11.35 & 77.73 & Dravidian & 15 & $1(6.667)$ & $9(64.286)$ & $5(35.714)$ & $0(0)$ & $23(82.143)$ & $5(17.857)$ & 1 \\
\hline Telagas & Andhra-Pradesh & 18.17 & 83.53 & Dravidians & 12 & $0(0)$ & $9(75)$ & $0(0)$ & $3(25)$ & $18(75)$ & $6(25)$ & 0.001634521 \\
\hline Thoti & Andhra-Pradesh & 16.51 & 80.64 & Dravidians & 29 & $0(0)$ & $20(68.966)$ & $0(0)$ & $9(31.034)$ & $40(68.966)$ & $18(31.034)$ & $2.23 E-08$ \\
\hline Naidu & Andhra-Pradesh & 13.22 & 79.6 & Dravidians & 21 & $11(52.381)$ & $9(90)$ & $1(10)$ & $0(0)$ & $19(95)$ & $1(5)$ & 1 \\
\hline Reddy & Andhra-Pradesh & 17.37 & 78.48 & Dravidians & 24 & $1(4.167)$ & $17(73.913)$ & $6(26.087)$ & $0(0)$ & $40(86.957)$ & $6(13.043)$ & 1 \\
\hline Mudaliar & Tamilnadu & 12.92 & 79.13 & Dravidians & 48 & $3(6.25)$ & 41(91.111) & $0(0)$ & $4(8.889)$ & 82(91.111) & $8(8.889)$ & $1.92 E-06$ \\
\hline Gammavokklu & Karnataka & 12.93 & 74.83 & Dravidians & 19 & $4(21.053)$ & $13(86.667)$ & $2(13.333)$ & $0(0)$ & $28(93.333)$ & $2(6.667)$ & 1 \\
\hline Vysya & Andhra-Pradesh & 14.68 & 77.65 & Dravidians & 60 & $10(16.667)$ & $40(80)$ & $10(20)$ & $0(0)$ & $90(90)$ & $10(10)$ & 1 \\
\hline Gawli & Karnataka & 13.33 & 74.77 & Dravidians & 89 & $10(11.236)$ & $63(79.747)$ & $10(12.658)$ & $6(7.595)$ & $136(86.076)$ & $22(13.924)$ & 0.000412713 \\
\hline Medari & Andhra-Pradesh & 16.56 & 80.61 & Dravidians & 4 & $0(0)$ & $3(75)$ & $1(25)$ & $0(0)$ & $7(87.5)$ & $1(12.5)$ & 1 \\
\hline Madar & Karnataka & 15.33 & 75.05 & Dravidians & 70 & $9(12.857)$ & $55(90.164)$ & 1(1.639) & $5(8.197)$ & $111(90.984)$ & $11(9.016)$ & $4.75 E-07$ \\
\hline Patkar & Andhra-Pradesh & 15.8 & 78.1 & Dravidians & 20 & $1(5)$ & 12(63.158) & $0(0)$ & $7(36.842)$ & $24(63.158)$ & $14(36.842)$ & $5.21 E-06$ \\
\hline Raj-Gond & Madhya-Pradesh & 23.87 & 78.7 & Dravidians & 28 & $19(67.857)$ & $9(100)$ & $0(0)$ & $0(0)$ & $18(100)$ & $0(0)$ & 1 \\
\hline Adhiyan & Tamilnadu & 13.72 & 79.41 & Dravidians & 44 & $4(9.091)$ & $37(92.5)$ & $3(7.5)$ & $0(0)$ & $77(96.25)$ & $3(3.75)$ & 1 \\
\hline Kurumba & Tamilnadu & 12.94 & 79.09 & Dravidians & 15 & $2(13.333)$ & $11(84.615)$ & $2(15.385)$ & $0(0)$ & $24(92.308)$ & $2(7.692)$ & 1 \\
\hline Chenchu & Andhra-Pradesh & 17.37 & 78.47 & Dravidians & 27 & $2(7.407)$ & $17(68)$ & $0(0)$ & $8(32)$ & $34(68)$ & $16(32)$ & 0 \\
\hline Kurumba & Madhya-Pradesh & 22.71 & 75.83 & Dravidians & 26 & $6(23.077)$ & $14(70)$ & $0(0)$ & $6(30)$ & $28(70)$ & $12(30)$ & $6.94 E-06$ \\
\hline Vaddera & Andhra-Pradesh & 18.72 & 79.48 & Dravidians & 8 & $0(0)$ & $5(62.5)$ & $0(0)$ & $3(37.5)$ & $10(62.5)$ & $6(37.5)$ & 0.006993007 \\
\hline Brahmin-Tiwari & Uttar-Pradesh & 25.73 & 82.68 & Indo-European & 44 & $13(29.545)$ & $28(90.323)$ & $3(9.677)$ & $0(0)$ & 59(95.161) & $3(4.839)$ & 1 \\
\hline Kashmiri pandit & JammuKashmir & 34.37 & 75.83 & Indo-European & 21 & $0(0)$ & $17(80.952)$ & $3(14.286)$ & $1(4.762)$ & $37(88.095)$ & $5(11.905)$ & 0.235 \\
\hline Bhil & Gujarat & 23.03 & 72.67 & Indo-European & 4 & $0(0)$ & $4(100)$ & $0(0)$ & $0(0)$ & $8(100)$ & $0(0)$ & 1 \\
\hline Gamit & Gujrat & 21.17 & 72.83 & Indo-European & 45 & $7(15.556)$ & $35(92.105)$ & $3(7.895)$ & $0(0)$ & 73(96.053) & $3(3.947)$ & 1 \\
\hline Tharu & Uttarakhand & 29.38 & 79.5 & Indo-European & 30 & $3(10)$ & $23(85.185)$ & $3(11.111)$ & $1(3.704)$ & $49(90.741)$ & $5(9.259)$ & 0.183 \\
\hline Warli & Maharastra & 19.17 & 72.95 & Indo-European & 70 & $7(10)$ & 48(76.19) & $15(23.81)$ & $0(0)$ & $111(88.095)$ & $15(11.905)$ & 0.5832885 \\
\hline Baiswar & Uttar-Pradesh & 25.15 & 82.6 & Indo-Europeans & 40 & $6(15)$ & $23(67.647)$ & $11(32.353)$ & $0(0)$ & $57(83.824)$ & $11(16.176)$ & 0.5620674 \\
\hline
\end{tabular}




\begin{tabular}{|c|c|c|c|c|c|c|c|c|c|c|c|c|}
\hline Pandit & Haryana & 29.96 & 76.87 & Indo-Europeans & 40 & $12(30)$ & $23(82.143)$ & $1(3.571)$ & $4(14.286)$ & $47(83.929)$ & $9(16.071)$ & 0.000129726 \\
\hline Bhilala & Madhya-Pradesh & 22.6 & 75.3 & Indo-Europeans & 49 & $9(18.367)$ & $33(82.5)$ & $5(12.5)$ & $2(5)$ & $71(88.75)$ & $9(11.25)$ & 0.05670192 \\
\hline Chakhesang_Naga & Nagaland & 26.12 & 94.48 & Tibeto-Burmans & 33 & $19(57.576)$ & $14(100)$ & $0(0)$ & $0(0)$ & $28(100)$ & $0(0)$ & 1 \\
\hline Naga-sema & Nagaland & 25.7 & 93.81 & Tibeto-Burmans & 40 & $21(52.5)$ & $16(84.211)$ & $3(15.789)$ & $0(0)$ & $35(92.105)$ & $3(7.895)$ & 1 \\
\hline Mizo & Mizoram & 23.2 & 92.83 & Tibeto-Burmans & 23 & $7(30.435)$ & $13(81.25)$ & $3(18.75)$ & $0(0)$ & $29(90.625)$ & $3(9.375)$ & 1 \\
\hline
\end{tabular}


Table 2. Distribution of novel non-synonymous mutation L362V, observed in exon-7 of CYP2C9

\begin{tabular}{|c|c|c|c|c|c|c|c|c|c|c|c|c|}
\hline \multirow[b]{2}{*}{ Populations } & \multirow[b]{2}{*}{ State } & \multirow[b]{2}{*}{ Lat. } & \multirow[b]{2}{*}{ Long. } & \multirow[b]{2}{*}{ Linguistic } & \multirow[b]{2}{*}{$\begin{array}{c}\text { Sample } \\
\text { size }\end{array}$} & \multicolumn{6}{|c|}{ number of individuals (Genotype/Allele percentage): Novel; Leu>Val } & \multirow[b]{2}{*}{$\begin{array}{c}\text { HWE P- } \\
\text { value }\end{array}$} \\
\hline & & & & & & $\begin{array}{l}\text { Missing } \\
\text { data }\end{array}$ & CC & CG & GG & C & G & \\
\hline Mahli & Jharkhand & 23.46 & 85 & Austro-Asiatic & 38 & $4(21.053)$ & $15(100)$ & $0(0)$ & $0(0)$ & $30(100)$ & $0(0)$ & 1 \\
\hline Ho & Jharkhand & 23.35 & 85.33 & Austro-Asiatics & 67 & $3(6.25)$ & 41(91.111) & $0(0)$ & $4(8.889)$ & 82(91.111) & $8(8.889)$ & $1.92 \mathrm{E}-06$ \\
\hline Gond & Madhya-Pradesh & 26.12 & 77.4 & Austro-Asiatics & 38 & $11(52.381)$ & $10(100)$ & $0(0)$ & $0(0)$ & $20(100)$ & $0(0)$ & 1 \\
\hline Gond & Chattisgarh & 19.87 & 81.6 & Austro-Asiatics & 37 & $7(18.421)$ & $31(100)$ & $0(0)$ & $0(0)$ & $62(100)$ & $0(0)$ & 1 \\
\hline Kharia & Chattisgarh & 85.44 & 23.33 & Austro-Asiatics & 86 & $13(29.545)$ & $31(100)$ & $0(0)$ & $0(0)$ & $62(100)$ & $0(0)$ & 1 \\
\hline Adi-Dravidar & Tamilnadu & 11.35 & 77.73 & Dravidian & 15 & $7(15.556)$ & $38(100)$ & $0(0)$ & $0(0)$ & $76(100)$ & $0(0)$ & 1 \\
\hline Kolhas & Andhra-Pradesh & 14.46 & 79.98 & Dravidian & 14 & $2(14.286)$ & $12(100)$ & $0(0)$ & $0(0)$ & $24(100)$ & $0(0)$ & 1 \\
\hline Reddy & Andhra-Pradesh & 17.37 & 78.48 & Dravidians & 24 & $6(23.077)$ & $14(70)$ & $0(0)$ & $6(30)$ & $28(70)$ & $12(30)$ & 6.94E-06 \\
\hline Thoti & Andhra-Pradesh & 16.51 & 80.64 & Dravidians & 29 & $12(30)$ & $23(82.143)$ & $1(3.571)$ & $4(14.286)$ & $47(83.929)$ & $9(16.071)$ & 0.000129726 \\
\hline Raj-Gond & Madhya-Pradesh & 23.87 & 78.7 & Dravidians & 28 & $2(2.985)$ & $63(96.923)$ & $0(0)$ & $2(3.077)$ & 126(96.923) & $4(3.077)$ & 0.000183117 \\
\hline Chenchu & Andhra-Pradesh & 17.37 & 78.47 & Dravidians & 27 & $9(18.367)$ & $38(95)$ & $0(0)$ & $2(5)$ & $76(95)$ & $4(5)$ & 0.000493178 \\
\hline Kurumba & Madhya-Pradesh & 22.71 & 75.83 & Dravidians & 26 & $9(45)$ & $9(81.818)$ & $0(0)$ & $2(18.182)$ & $18(81.818)$ & $4(18.182)$ & 0.007518797 \\
\hline Kurumba & Tamilnadu & 12.94 & 79.09 & Dravidians & 15 & $0(0)$ & $20(95.238)$ & $0(0)$ & $1(4.762)$ & $40(95.238)$ & $2(4.762)$ & 0.02439024 \\
\hline Gammavokklu & Karnataka & 12.93 & 74.83 & Dravidians & 19 & $3(10)$ & $25(92.593)$ & $1(3.704)$ & $1(3.704)$ & 51(94.444) & $3(5.556)$ & 0.05660377 \\
\hline Adhiyan & Tamilnadu & 13.72 & 79.41 & Dravidians & 44 & $2(7.407)$ & $25(100)$ & $0(0)$ & $0(0)$ & $50(100)$ & $0(0)$ & 1 \\
\hline Gawli & Karnataka & 13.33 & 74.77 & Dravidians & 89 & $4(9.091)$ & $40(100)$ & $0(0)$ & $0(0)$ & $80(100)$ & $0(0)$ & 1 \\
\hline Madar & Karnataka & 15.33 & 75.05 & Dravidians & 70 & $0(0)$ & $12(100)$ & $0(0)$ & $0(0)$ & $24(100)$ & $0(0)$ & 1 \\
\hline Medari & Andhra-Pradesh & 16.56 & 80.61 & Dravidians & 4 & $19(67.857)$ & $9(100)$ & $0(0)$ & $0(0)$ & $18(100)$ & $0(0)$ & 1 \\
\hline Mudaliar & Tamilnadu & 12.92 & 79.13 & Dravidians & 48 & $1(5)$ & $19(100)$ & $0(0)$ & $0(0)$ & $38(100)$ & $0(0)$ & 1 \\
\hline Naidu & Andhra-Pradesh & 13.22 & 79.6 & Dravidians & 21 & $10(16.667)$ & $50(100)$ & $0(0)$ & $0(0)$ & $100(100)$ & $0(0)$ & 1 \\
\hline Patkar & Andhra-Pradesh & 15.8 & 78.1 & Dravidians & 20 & $19(57.576)$ & $14(100)$ & $0(0)$ & $0(0)$ & $28(100)$ & $0(0)$ & 1 \\
\hline Telagas & Andhra-Pradesh & 18.17 & 83.53 & Dravidians & 12 & $7(10)$ & $63(100)$ & $0(0)$ & $0(0)$ & $126(100)$ & $0(0)$ & 1 \\
\hline Vaddera & Andhra-Pradesh & 18.72 & 79.48 & Dravidians & 8 & $7(30.435)$ & $16(100)$ & $0(0)$ & $0(0)$ & $32(100)$ & $0(0)$ & 1 \\
\hline Vysya & Andhra-Pradesh & 14.68 & 77.65 & Dravidians & 60 & $1(4.167)$ & $23(100)$ & $0(0)$ & $0(0)$ & $46(100)$ & $0(0)$ & 1 \\
\hline Kashmiri pandit & Jammu Kashmir & 34.37 & 75.83 & Indo-European & 21 & $10(11.236)$ & $73(92.405)$ & $0(0)$ & $6(7.595)$ & $146(92.405)$ & $12(7.595)$ & $8.44 \mathrm{E}-10$ \\
\hline Warli & Maharastra & 19.17 & 72.95 & Indo-European & 70 & $9(12.857)$ & $56(91.803)$ & $0(0)$ & $5(8.197)$ & 112(91.803) & $10(8.197)$ & 4.32E-08 \\
\hline Bhil & Gujarat & 23.03 & 72.67 & Indo-European & 4 & $14(16.279)$ & $72(100)$ & $0(0)$ & $0(0)$ & $144(100)$ & $0(0)$ & 1 \\
\hline Brahmin-Tiwari & Uttar-Pradesh & 25.73 & 82.68 & Indo-European & 44 & $0(0)$ & $4(100)$ & $0(0)$ & $0(0)$ & $8(100)$ & $0(0)$ & 1 \\
\hline Gamit & Gujrat & 21.17 & 72.83 & Indo-European & 45 & $1(6.667)$ & $14(100)$ & $0(0)$ & $0(0)$ & $28(100)$ & $0(0)$ & 1 \\
\hline Tharu & Uttarakhand & 29.38 & 79.5 & Indo-European & 30 & $0(0)$ & $29(100)$ & $0(0)$ & $0(0)$ & $58(100)$ & $0(0)$ & 1 \\
\hline
\end{tabular}




\begin{tabular}{|c|c|c|c|c|c|c|c|c|c|c|c|c|}
\hline Pandit & Haryana & 29.96 & 76.87 & Indo-Europeans & 40 & $1(2.174)$ & $35(77.778)$ & $0(0)$ & $10(22.222)$ & 70(77.778) & $20(22.222)$ & $6.26 \mathrm{E}-11$ \\
\hline Baiswar & Uttar-Pradesh & 25.15 & 82.6 & Indo-Europeans & 40 & $2(13.333)$ & $13(100)$ & $0(0)$ & $0(0)$ & $26(100)$ & $0(0)$ & 1 \\
\hline Bhilala & Madhya-Pradesh & 22.6 & 75.3 & Indo-Europeans & 49 & $0(0)$ & $4(100)$ & $0(0)$ & $0(0)$ & $8(100)$ & $0(0)$ & 1 \\
\hline Naga-sema & Nagaland & 25.7 & 93.81 & Tibeto-Burmans & 40 & $4(10.526)$ & $33(97.059)$ & $0(0)$ & $1(2.941)$ & $66(97.059)$ & $2(2.941)$ & 0.01492537 \\
\hline Chakhesang_Naga & Nagaland & 26.12 & 94.48 & Tibeto-Burmans & 33 & $8(21.622)$ & $28(96.552)$ & $0(0)$ & $1(3.448)$ & 56(96.552) & $2(3.448)$ & 0.01754386 \\
\hline Mizo & Mizoram & 23.2 & 92.83 & Tibeto-Burmans & 23 & $0(0)$ & $8(100)$ & $0(0)$ & $0(0)$ & $16(100)$ & $0(0)$ & 1 \\
\hline
\end{tabular}



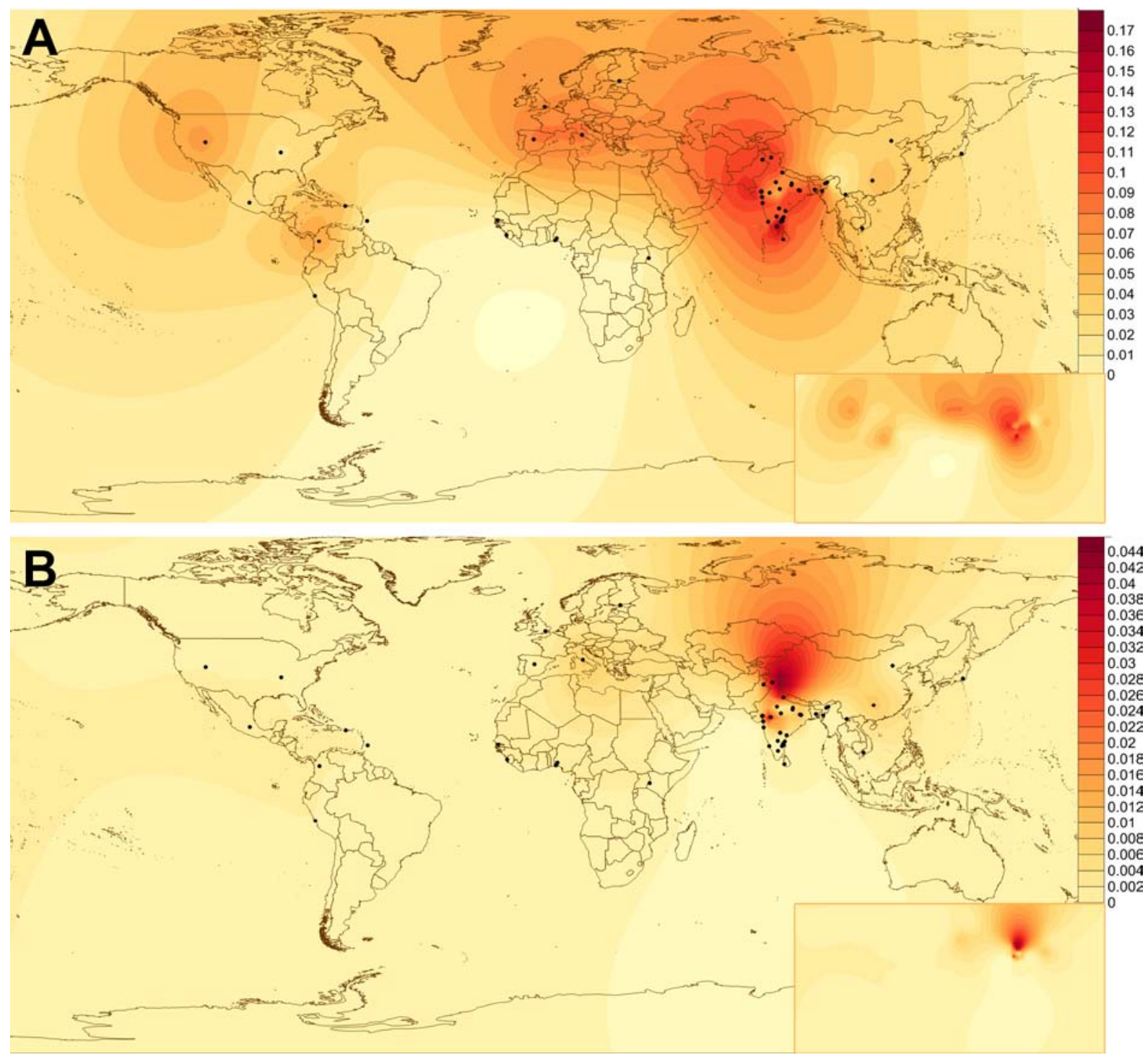


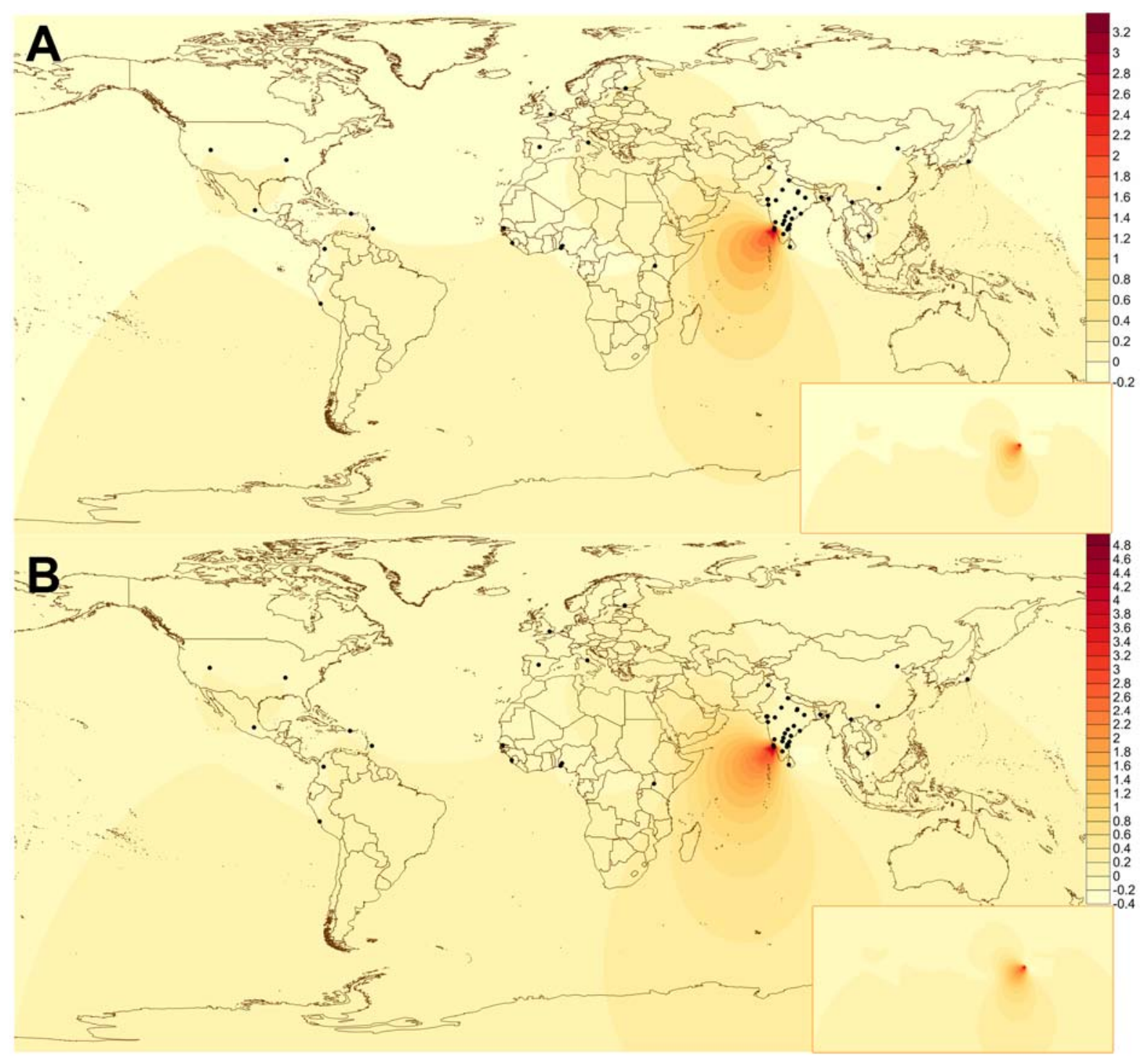


A

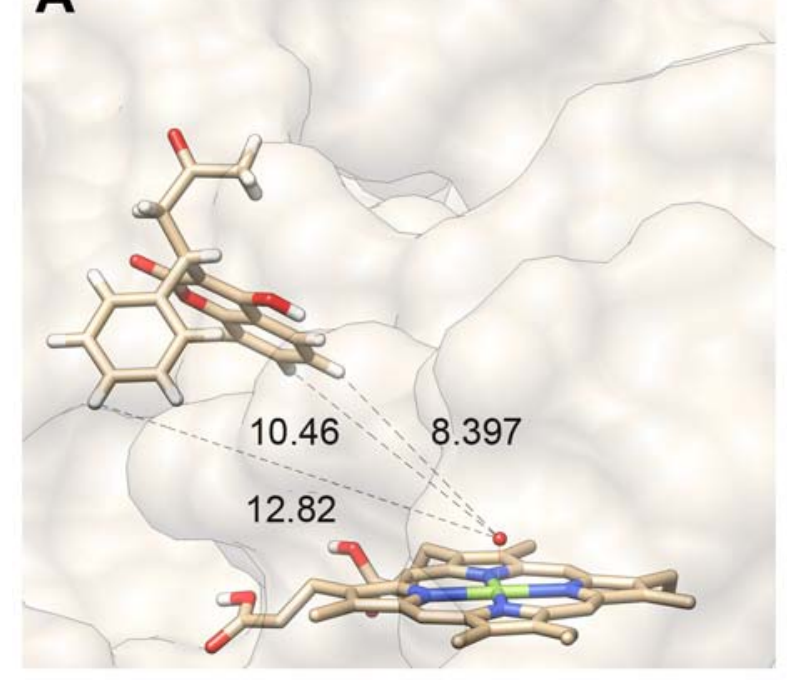

B

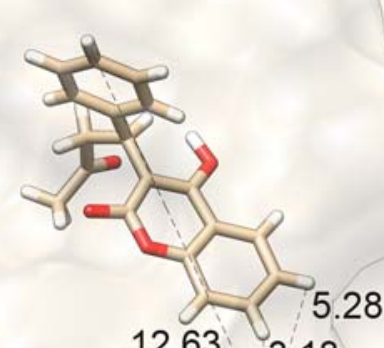

12.63

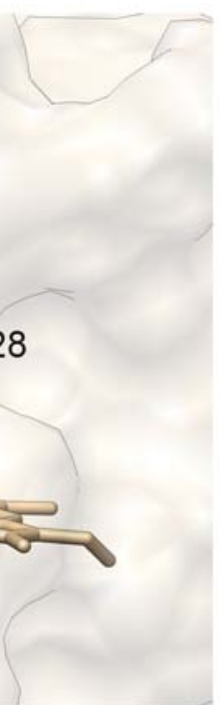


bioRxiv preprint doi: https://doi.org/10 1101/113993; this version posted March 5, 2017. The copyright holder for this preprint (which was not certified by peer review) is the author/funder. All rights reserved. No reuse allowed without permission.
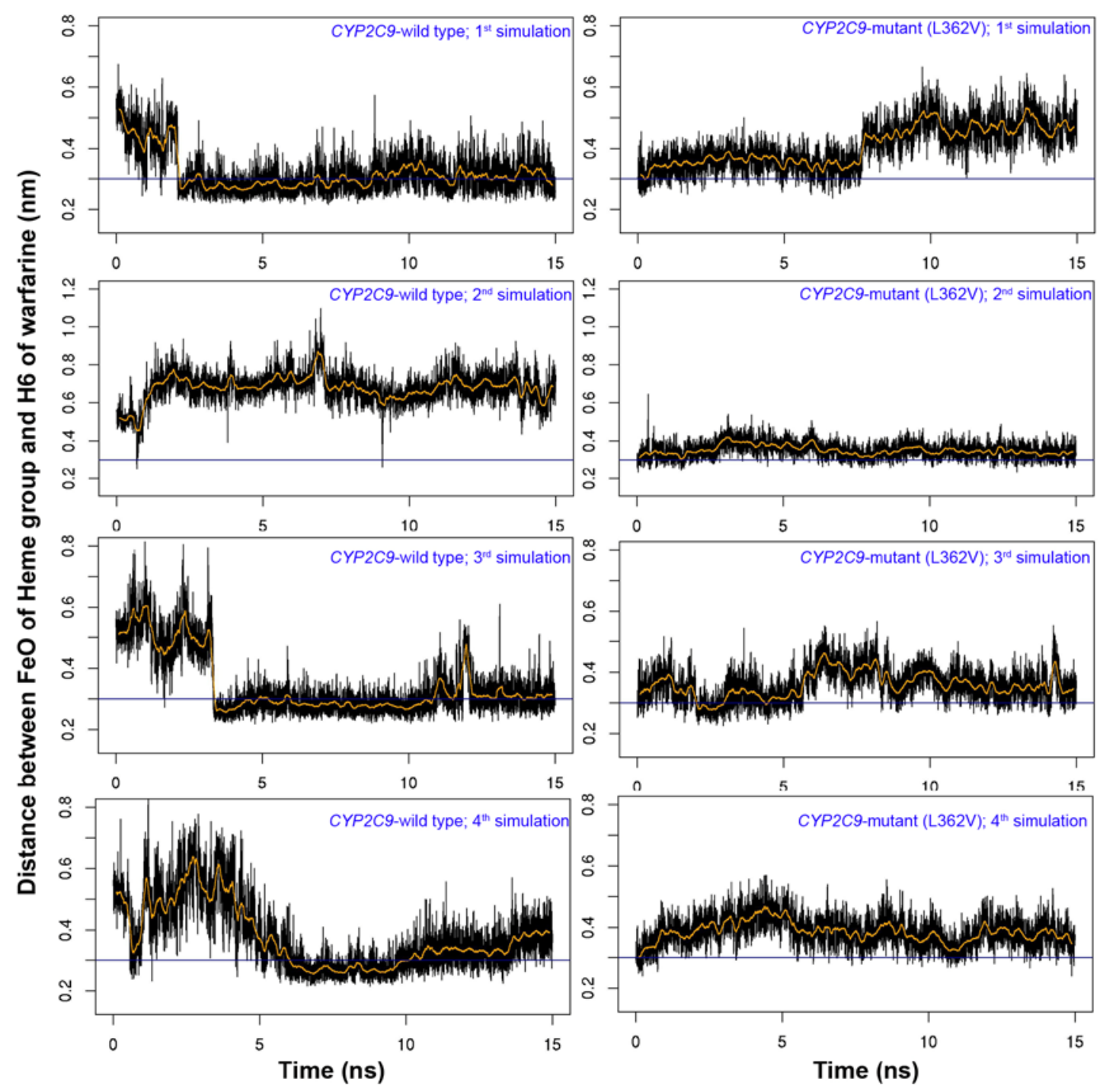
bioRxiv preprint doi: https://doi.org/10 1101/113993; this version posted March 5, 2017. The copyright holder for this preprint (which was not certified by peer review) is the author/funder. All rights reserved. No reuse allowed without permission.
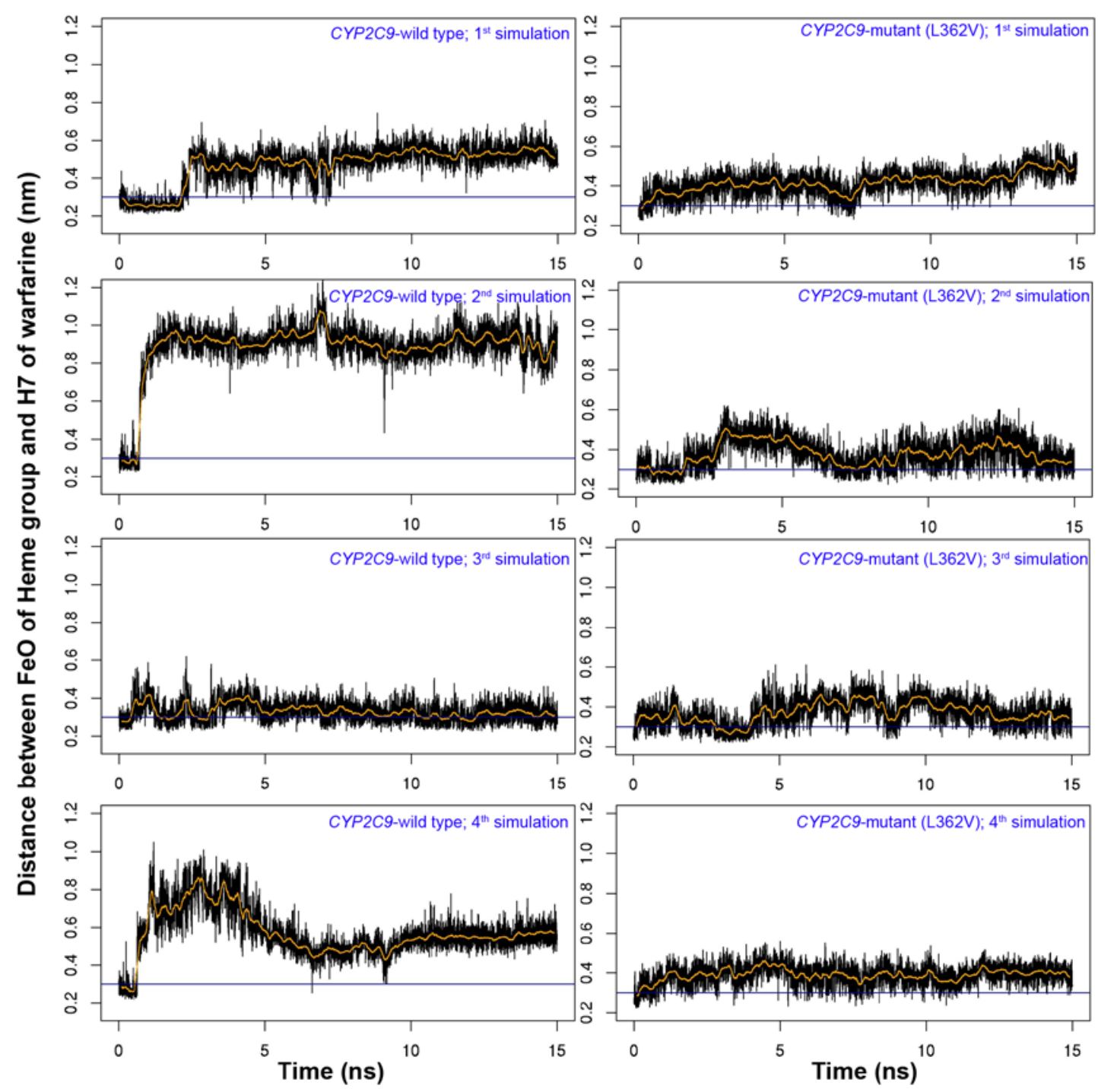